\title{
Prevalence of Nosema microsporidians in commercial bumblebees (Bombus terrestris) is not related to the intensity of their use at the landscape scale
}

\author{
Alejandro Trillo ${ }^{1}$, Mark J. F. Brown ${ }^{2}$, Montserrat VILÀ ${ }^{1}$ \\ ${ }^{1}$ Estación Biológica de Doñana (EBD-CSIC), Avda. Américo Vespucio 26, Isla de la Cartuja, E-41092, Sevilla, Spain \\ ${ }^{2}$ School of Biological Sciences, Royal Holloway University of London, Egham TW20 0EX, UK
}

Received 25 July 2018 - Revised 14 January 2019 - Accepted 25 February 2019

\begin{abstract}
The use of commercial bumblebees to aid crop pollination may result in overcrowding of agricultural landscapes by pollinators. Consequently, transmission of parasites between pollinators via shared flowers may be substantial. In SW Spain, we assessed the initial infection status of commercial Bombus terrestris colonies and then explored spatial and seasonal influences on changes in parasite prevalence across a landscape where bumblebee colonies are intensively used to pollinate berry crops. Colonies were placed inside strawberry greenhouse crops and in woodlands adjacent and distant to crops, in winter and in spring, as representative periods of high and low use of colonies, respectively. Worker bumblebees were collected from colonies upon arrival from a producer and 30 days after being placed in the field. The abdomen of each bumblebee was morphologically inspected for a range of internal parasites. Upon arrival, $71 \%$ of the colonies were infected by spores of Nosema. Three bumblebees from two colonies harboured Apicystis bombi spores at the end of their placement in woodlands adjacent to the crops. Nosema colony prevalence did not change significantly either among sites or between seasons. We found no evidence for the density of commercial B. terrestris impacting Nosema prevalence in those commercial colonies, but our results highlight the potential risk for parasites to be transmitted from commercial bumblebees to native pollinators.
\end{abstract}

\section{agricultural landscape / Apicystis bombi / Fragaria $\times$ ananassa / parasite}

\section{INTRODUCTION}

In the last half-century, there has been an increase in the expansion of pollinator-dependent crops (Aizen et al., 2008) that has required a parallel demand for commercially produced bees (Potts et al., 2016). Bumblebees (Bombus sp.) started to be commercially produced in Europe in the late 1980 s, to replace the costly mechanical pollination of tomatoes (Solanum lycopersicum) (van Ravestijn and van der Sande, 1991; Velthuis and van Doorn,

Electronic supplementary material The online version of this article (https://doi.org/10.1007/s13592-019-00637-4) contains supplementary material, which is available to authorized users.

Corresponding author: A. Trillo, atrilloig@gmail.com Manuscript editor: Peter Rosenkranz
2006). Quickly, bumblebee breeding techniques advanced and colonies were mass-produced and transported worldwide, where they currently pollinate over 20 different pollinator-dependent crops. Over two million bumblebee colonies are produced annually (Graystock et al., 2016a).

The use of commercial pollinators such as bumblebees to aid crop pollination is not free of environmental risks. For instance, queens of commercial bumblebees have become established in many parts of the world (Matsumura et al., 2004; Morales et al., 2013), and there is empirical evidence showing competition for nest sites with other native bumblebee queens in the lab (Ono, 1997) and in the field (Inoue et al., 2008). In addition, commercial bumblebees may compete for food with other native pollinators (Matsumura et al., 2004; Morales et al., 2013), as well as 
promote the spread of parasites via shared flowers (Colla et al., 2006; Meeus et al., 2011; SchmidHempel et al., 2014).

Several bee parasite species have been found in commercial bumblebee colonies. In 1999, Goka et al. (2000) found for the first time the presence of a parasite, Locustacarus buchneri, in commercially produced Bombus terrestris colonies upon arrival in Japan from an overseas supplier. The presence of this parasite has been linked to shorter lifespan (Otterstatter and Whidden, 2004) and changes in the behaviour of bumblebees (Otterstatter et al., 2005). Further studies have reported that commercial bumblebee colonies frequently have a range of bumblebee parasites (Graystock et al., 2013a; Murray et al., 2013) and even honeybee parasites (Graystock et al., 2013a), with the latter probably via the consumption of honeybee pollen by reared bumblebees (Goulson and Hughes, 2015). Importantly, the use of commercial pollinators in crops produces high densities of pollinators not only in the agricultural fields or greenhouses but also in adjacent natural areas (Ishii et al., 2008; González-Varo and Vilà, 2017; Trillo et al., 2018). Presumably, in those areas, the rate of parasite transmission among pollinators will rise, because high densities of hosts provide ideal conditions for the spread of parasites (Arneberg et al., 1998). In fact, several studies have shown, through the collection of freeflying bumblebees, high prevalence of parasites in sites adjacent to greenhouses where commercial bumblebees are used compared with sites distant to those greenhouses (Colla et al., 2006; Murray et al., 2013) or in greenhouses absent of such commercial bumblebees (Graystock et al., 2014), although there is also evidence against this (Whitehorn et al., 2013).

To partially reduce the impact of commercial bumblebees on native pollinator populations and because healthy bumblebees may perform better, as is seen with honeybees (Geslin et al., 2017), producers are under pressure to produce parasitefree bumblebee colonies. In this study, we first examined whether commercially produced $B$. terrestris colonies, used to pollinate berry crops in Huelva (SW Spain), carried parasites upon arrival from a producer. We morphologically searched for five common internal bee parasites: larvae of the family Conopidae and Braconidae, L. buchneri, Apicystis bombi and parasites of the genus Nosema, which all potentially affect bumblebee health. For instance, larvae of parasitic flies lead to bee death (Schmid-Hempel and SchmidHempel, 1996); L. buchneri likely reduces the lifespan of individually infected host (Otterstatter and Whidden, 2004); A. bombi is linked to the deterioration of the fat body (Graystock et al., 2016b; Macfarlane et al., 1995) and most Nosema species reduce worker survival and colony size (Otti and Schmid-Hempel, 2007; Rutrecht and Brown, 2009; Graystock et al., 2013a). We then experimentally tested spatial and seasonal influences on changes in the prevalence of these parasites across a landscape where bumblebee colonies are intensively used. Importantly, L. buchneri, A. bombi and Nosema are likely to be transmitted among pollinators via shared flowers (Durrer and Schmid-Hempel, 1994; Goka et al., 2006; Graystock et al., 2015). Colonies were placed inside strawberry crops and in woodlands adjacent and distant to those crops in January (winter) and again in April (spring), as representative periods of high and low use of bumblebee colonies in berry crops, respectively. We expected parasite prevalence to be highest with high densities of commercial bumblebees in the landscape, that is (1) higher levels of prevalence at sites inside and adjacent to greenhouse crops than distant and (2) higher levels in winter than in spring because of the greater use of colonies in winter.

\section{MATERIALS AND METHODS}

\subsection{Study system}

The study was conducted in the Guadalquivir Valley in the province of Huelva (SW Spain). In this region, there are large intensively cultivated areas of berries ( $9500 \mathrm{ha}$ ), especially strawberries ( $\sim 70 \%$ of the total area devoted to berry crops) (Freshuelva, 2015). Strawberries are cultivated in semi-open polytunnel greenhouses with open sides from November to May. In order to aid crop pollination, farmers use commercial bumblebees (Bombus terrestris ). Notably, bumblebee colonies are especially used at the beginning of the 
flowering period (i.e. in winter; personal observations) due to major revenues and worse weather conditions than in spring. The most common remaining natural habitat patches across berry crops are woodlands composed of a rich flora of entomophilous Mediterranean shrubs and herbs, which provide flowers throughout the strawberry cultivation period (Herrera, 1988).

\subsection{Experimental design}

In 2015, we purchased 48 B. terrestris colonies from Koppert Biological Systems, one of the main producers in Europe and specifically in this region. Each colony consisted of a plastic box within a cardboard container, with syrup solution provided ad libitum. Each colony included a queen and $\sim 100$ workers.

First, to quantify colony parasite prevalence, at the arrival of the colonies (period 'before'), we collected 10 workers from each colony. Each worker was frozen in an individual clean vial at $20{ }^{\circ} \mathrm{C}$ for later analyses.

Second, to investigate the changes in colony parasite prevalence across the landscape, we placed two colonies each in four strawberry crops ('inside') and in eight woodlands, four adjacent to the selected strawberry crops ( $50 \mathrm{~m}$; 'adjacent') and four without berry crops in the surrounding 2$\mathrm{km}$ radius landscape ('distant') (Figure 1). We chose a 2-km buffer radius because most bumblebee foraging flights do not exceed this distance (Osborne et al., 2008). The surrounding landscape for inside and adjacent plots had a high berry crop cover (overall mean $\pm \mathrm{SE}=48 \pm 5.6 \%$; see Table S1). Inside/adjacent plots and distant plots are representative of contrasting landscapes in terms of commercial bumblebee colony density. The density is high and absent in those landscapes, respectively. In fact, commercial bumblebees are frequently observed in landscapes with berry crop cover, rather than when berry crop cover is absent in the landscapes (Trillo et al., 2019). The average ( \pm SE) distance between adjacent and distant woodland plots was $5.9 \pm$ $1.0 \mathrm{~km}$ (range, $3.1-11.4 \mathrm{~km}$ ). This distance meets the independence criteria to avoid spatial pseudoreplication between non-paired plots.
Third, to investigate the seasonal change effects, the experiment was conducted in January ('winter') and repeated in April ('spring'), as representative periods of high and low use of bumblebee colonies in strawberry crops, respectively. Here, the climate is typically Mediterranean with mild winters and warm springs (AEMET, 2015). These two seasons also differ in wild floral resources. The flowering peak is in spring when the floral richness and density are almost triple that in winter (Trillo et al., 2019). Wild pollinator species occur as flowering plant species thrive (Herrera, 1988).

In each season, we placed two colonies of bumblebees in the centre of each plot. Bumblebees were allowed to forage for 30 days. In strawberry crops, the two colonies were hung between four separate greenhouses. The distance between the two colonies within a plot was $\sim 20 \mathrm{~m}$. In woodland plots, the two colonies were hidden in wooden boxes to avoid predation. At the end of the experiment, we collected 10 bumblebee workers per colony returning to it (period 'after') over 2 days using aerial nets. Bumblebees were kept in individual clean vials with ice until arrival at the lab where they were stored at $-20{ }^{\circ} \mathrm{C}$.

\subsection{Parasite screening}

The abdomen of each bumblebee was dissected and inspected under a magnifying lens for larvae of parasitic conopid flies (Conopidae, Diptera) and braconid wasps of the genus Syntretus (Braconidae, Hymenoptera), and the air sacs were specifically inspected for the tracheal mite Locustacarus buchneri (Podapolipidae) (Yoneda et al., 2008). Then, a piece $(0.2 \mathrm{~cm} \times 0.2 \mathrm{~cm}$, approx.) of the fat body was dissected out from each bumblebee and mounted on a slide (note that the gut was not included for these analyses). By screening only the fat body, we were able to confirm that we were detecting true infections, not just passage through the gut by vectored spores. We completely screened each slide at $\times$ 400 magnification for the presence of spores of the neogregarine Apicystis bombi (Lipotrophidae) and microsporidians of the genus Nosema (Nosematidae). We estimated the parasite prevalence (presence or absence) instead of individual 

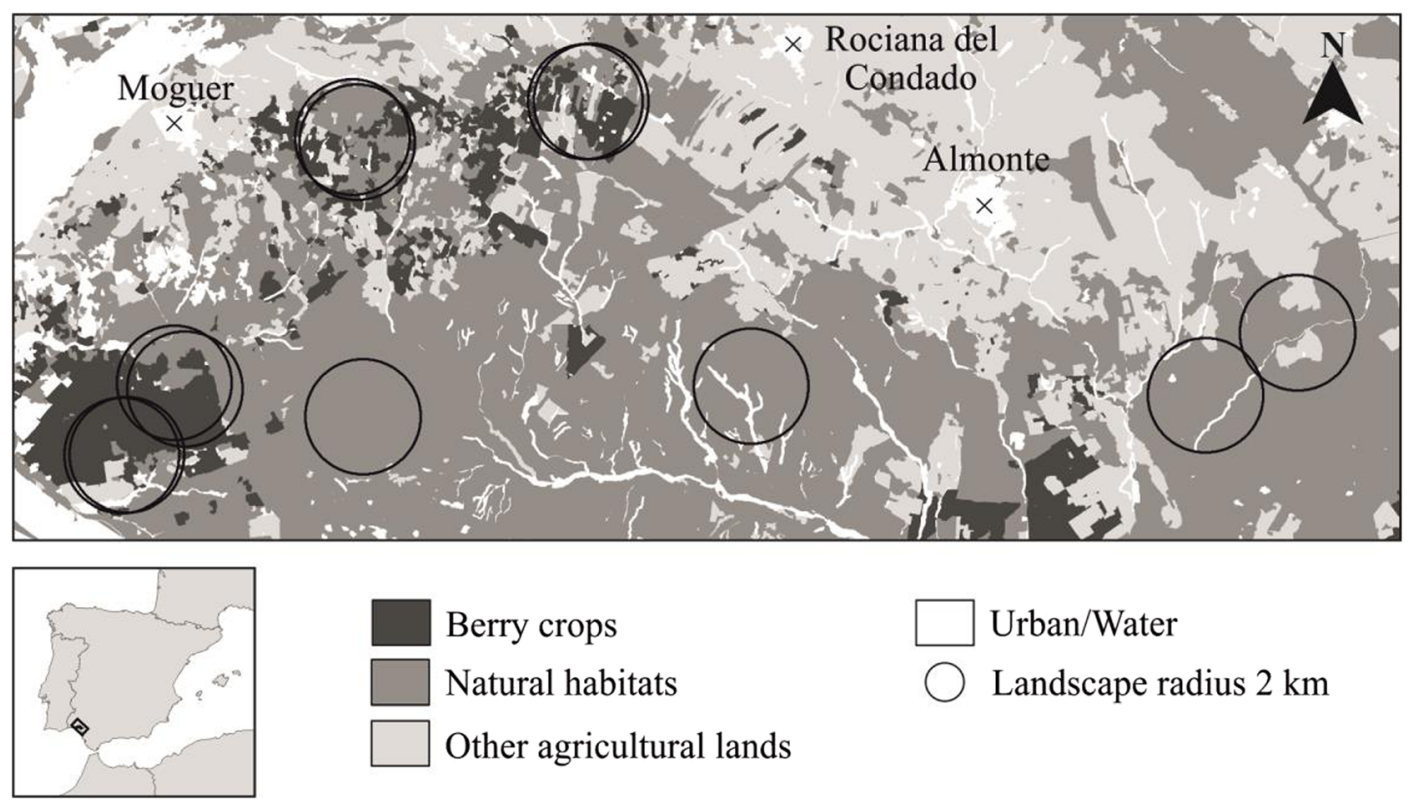

Berry crops

Natural habitats

Other agricultural lands

Figure 1. Geographical distribution of plots inside, adjacent and distant to berry crops located in the province of Huelva (SW Spain). Names denote towns.

infection levels (abundance) because the latter is influenced by many confounding factors that drive infection intensity (Rutrecht and Brown, 2009).

\subsection{Statistical analyses}

Only Nosema infections (Table S2) were statistically analysed, because the remaining parasites showed no or very low prevalence in the colonies (see results). Nosema prevalence was calculated estimating the percentage of bumblebees infected taking into account the 10 individuals collected per colony. A linear mixed model (LMM; Gaussian error distribution based on homogeneity in the residuals) was used to analyse whether changes in Nosema prevalence were related to our experimental setting. The difference in Nosema prevalence in the colonies before and after being placed in the field was used as the response variable. Season (winter/spring), plot type (inside, adjacent and distant) and their interaction were included as fixed factors in the model, while study plot was included as a random factor to account for the paired design between inside and adjacent plots and the re-sampled plots in winter and in spring (see Table S3 for the $\mathrm{R}$ code). All statistical analyses were conducted in R (v.3.1.3, R Core Team, 2014). We used the package lmerTest (Kuznetsova et al., 2013) for the LMM and Satterthwaite's approximations for $F$ and $p$ values.

\section{RESULTS}

In total, over the two seasons, we screened 919 bumblebee workers. We missed one colony and several individuals from other colonies due to low colony activity. On average ( $\pm \mathrm{SE}$ ), we collected $19.55 \pm 0.13$ (range, 16-20) bumblebees per colony. None of the bumblebees were infected by larvae of parasitic conopid flies (Conopidae, Diptera), braconid wasps of the genus Syntretus (Braconidae, Hymenoptera) or the tracheal mite, Locustacarus buchneri. The prevalence of Apicystis bombi was extremely low; only three bumblebees harboured spores in their fat body, and these were collected from two colonies at the end of their placement in adjacent woodlands.

In contrast, spores of Nosema were found in $58.3 \%$ (14 out of 24 colonies) of colonies in winter and in $83.3 \%$ (20 out of 24) in spring at 
the start of each experimental block; that is, upon arrival from the producer prior to their placement in the field. The average Nosema prevalence per colony in the before period was $14.0 \pm 3.4 \%$ (mean $\pm \mathrm{SE}$, hereafter) in winter, and $19.7 \pm$ $3.2 \%$ in spring. The average Nosema prevalence in the after period was $10.2 \pm 2.3 \%$ in winter and $26.4 \pm 6.6 \%$ in spring. Neither the season $\left(F_{1}\right.$, $\left.{ }_{35}=2.88, p<0.10\right)$ nor the distance $\left(F_{2,19}=\right.$ $0.25, p<0.79)$ or their interaction $\left(F_{2,35}=0.50\right.$, $p<0.61)$ had a significant effect on the changes in Nosema colony prevalence between periods (Figure 2a, b).

\section{DISCUSSION}

The use of commercial bumblebees has been linked to the decline of several native pollinator species (Cameron et al., 2011; Morales et al., 2013; Schmid-Hempel et al., 2014). Among the mechanisms behind this decline, parasite spillover from commercial to native pollinator populations may play a substantial role (Meeus et al., 2011). Mass commercial breeding programmes may facilitate the probability of parasite transmission among hosts, as companies usually handle high densities of bumblebees in their facilities. In parallel, the provision of ad libitum food may facilitate the reproduction of infected hosts (Brown et al., 2000). Furthermore, even in the case that commercial bumblebees are parasite-free, they may act as reservoirs for parasites in the field, through a spill-back mechanism, leading to an increase in parasite prevalence (Stout and Morales, 2009; Meeus et al., 2011).

Upon arrival, we found no evidence for the presence of larvae of parasitic conopid flies (Conopidae, Diptera) and braconid wasps of the genus Syntretus (Braconidae, Hymenoptera), or the tracheal mite, Locustacarus buchneri, in the screened Bombus terrestris colonies. Although the presence of larvae of parasitic insects has never been reported in commercial bumblebees, the tracheal mite, L. buchneri, was highly prevalent at the end of the twentieth century (Goka et al., 2000) spilling over to native bumblebees (Goka et al., 2006). However, it seems that producers have largely eliminated this parasite from commercial bumblebee colonies (Goka et al., 2006; Murray et al., 2013; although see Sachman-Ruiz et al., 2015). In addition, neither these parasitoids nor the tracheal mite, L. buchneri, were observed in bumblebees from the colonies after being placed in the field for a month. One explanation for this is that parasitoids of bumblebees might be at low abundance in our study sites, because native bumblebees (B. terrestris lusitanicus) are rare (Magrach

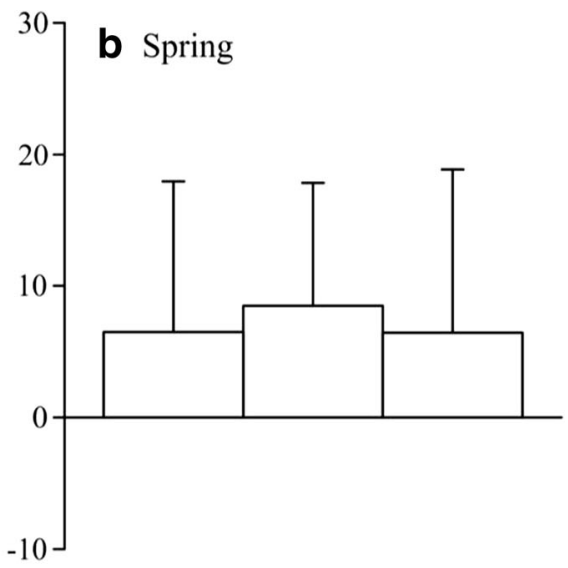

Inside Adjacent Distant

Figure 2. Mean (+ SE) change in Nosema prevalence in commercially produced bumblebee colonies before and after being placed in plots inside, adjacent $(\sim 50 \mathrm{~m})$ and distant $(>2 \mathrm{~km})$ to berry crops in winter (a) and in spring (b). Differences were not significant. 
et al., 2017; Trillo et al., 2019), as they are at the limit of their distributional range (Goulson, 2010). In fact, in this region, the density of commercial bumblebees is around four times greater than that of native bumblebees (Trillo et al., 2019). Another possible and complementary explanation for this low prevalence might be that when bumblebees are parasitized, they desert their colony (SchmidHempel and Müller, 1991). In addition, even though L. buchneri may be present in native bumblebees (although we note that there is no information in Spain; Jabal-Uriel et al. 2017), it might be very difficult to detect parasite spillover from native to managed bumblebees because native bumblebees are not abundant, as described above.

Similarly, there was no evidence for the presence of the neogregarine Apicystis bombi (Lipotrophidae) in the screened colonies upon arrival. However, three bumblebees were found to be infected after having been placed in the field. In other regions, the parasite A. bombi has been detected infecting commercial bumblebee colonies, although in a low number of colonies (Graystock et al., 2013b; Murray et al., 2013; although again, see Sachman-Ruiz et al., 2015). Native bumblebees can host $A$. bombi (Jabal-Uriel et al., 2017), but, as noted above, they are rare in our study region (Magrach et al., 2017; Trillo et al., 2019). In contrast, thousands of commercial colonies from at least three producers (Koppert, Biobest and Agrobio, personal observation) are used on an annual basis. Therefore, it is more likely that other commercial bumblebees infected by $A$. bombi transmitted the parasite to the bumblebee colonies we screened, rather than native bumblebees, or, more parsimoniously, our initial screen failed to detect it in arriving colonies.

In contrast, we found commercially produced bumblebee colonies to be heavily infected with parasites of the genus Nosema upon arrival from the producer. Other studies have also reported similar levels of prevalence with around threequarters of commercial colonies infected (Graystock et al., 2013a; Murray et al., 2013). Unfortunately, our methodology did not allow us to distinguish between the bumblebee parasite
$N$. bombi and the honeybee parasite $N$. ceranae. Both can infect bumblebees (Graystock et al., 2013a; Fürst et al., 2014).

Unexpectedly, our results showed no significant variation in Nosema infection rate at a colony level over time, as in a previous study that monitored wild bumblebees (Goulson et al., 2018), even in landscapes where commercial bumblebees were intensively used to pollinate crops. Even in parasite-free landscapes, one would expect that if commercial colonies are infected by a parasite, it spreads within the colony across time due to the high density of hosts and low genetic variability (Schmid-Hempel, 1998). We propose two potential explanations. On the one hand, bumblebees, in line with other social insects, have evolved social immune systems that combine prophylactic and activated responses to avoid, control or eliminate parasite infections (reviewed by Cremer et al., 2007). Both colony and individual (i.e. immunocompetence, reviewed by Schmid-Hempel 2005) defence mechanisms might be involved in maintaining roughly constant Nosema prevalence over time. On the other hand, it has been experimentally demonstrated that Nosema, specifically $N$. bombi, relies more on transmission through the larval stage than through transmission among adults (Rutrecht et al., 2007). If we consider that colonies were placed in the field for a month and that the total development of a bumblebee from larvae to adult is about 4-5 weeks (Alford, 1975), this could explain why we failed to detect an increase in prevalence. Imhoof and SchmidHempel (1999) showed an average delay to Nosema infection in commercial colonies placed in the field of $\sim 30$ days.

Our study showed, for the first time in Spain, that commercially produced bumblebee colonies can be infected by Nosema parasites prior to their deployment in the field. These parasites may reduce lifespan and have detrimental effects on bumblebee behaviour (Otti and Schmid-Hempel, 2007; Rutrecht and Brown, 2009; Graystock et al., 2013a). Because commercial bumblebees placed in semi-open greenhouses frequently forage in natural areas (Foulis and Goulson, 2014), they have the potential to spread the parasites into native 
pollinator populations (Colla et al., 2006; Murray et al., 2013). Despite the fact that there is some regulation about commercial bee colony health (e.g. for Europe, see 92/65/EEC in European Commission 1992), this regulation does not cover all parasites. This implies that commercial colonies can be highly infected by parasites such as Nosema, as our study show. Therefore, there is a need for the enforcement of more stringent protocols to preserve the health of commercial and native pollinators.

\section{ACKNOWLEDGMENTS}

We thank J. Angelidou, C. Apostolidou, A. Montero-Castaño, D. Ragel and E. Tsiripli for the field assistance and the farmers for letting us work on their lands. We thank J. Bagi and E.J. Bailes for the lab support. We would also like to thank the editor and the anonymous reviewers for their comments that significantly improved the manuscript.

\section{AUTHOR CONTRIBUTIONS}

$\mathrm{AT}$ and $\mathrm{MV}$ conceived this research and designed the experiments; MJFB participated in the design and interpretation of the data; AT performed the experiments, analyses and wrote the first draft of the manuscript; MJFB and MV edited and contributed to the writing of the manuscript. All authors read and approved the final manuscript.

\section{FUNDING INFORMATION}

Funding was provided by the Spanish Ministry of Economy and Competitiveness project FLORMAS ('Influence of mass flowering crops on pollinator biodiversity, project no CGL201233801') and by the Biodiversa-FACCE project ECODEAL ('Enhancing biodiversity-based ecosystem services to crops through optimised densities of green infrastructure in agricultural landscapes, project no PCIN-2014-048'). AT was supported by a Severo-Ochoa predoctoral fellowship (SVP-2013-067592) and by a Short Term Scientific Mission from the COST Action (FA1307:35075) for international mobility.

\section{COMPLIANCE WITH ETHICAL STANDARDS}

Conflict of interest The authors declare that they have no conflict of interest.

La prévalence de la microsporidie Nosema dans les colonies de bourdons commerciaux (Bombus terrestris) n'est pas liée à l'intensité de leur utilisation au niveau du paysage

Paysage agricole / Apicystis bombi / Fragaria $\times$ ananassa / parasite

Die Prävalenz von Nosemaerregern in kommerziellen Hummelvölkern (Bombus terrestris) steht nicht in Beziehung zur Intensität ihres Einsatzes auf der Landschaftsebene

Landschaftsebene / Apicystis bombi / Fragaria $\times$ ananassa / Parasiten

\section{REFERENCES}

AEMET (2015). Valores climatológicos normales. Huelva, Ronda Este. http://www.aemet.es/es/ (Accessed 01 September 2015).

Aizen, M. A., Garibaldi, L. A., Cunningham, S. A., Klein, A. M. (2008). Long-term global trends in crop yield and production reveal no current pollination shortage but increasing pollinator dependency. Curr. Biol. 18 (20), 1572-1575.

Alford, D. V. (1975). Bumblebees. Davis-Poynter, London.

Arneberg, P., Skorping, A., Grenfell, B., Read, A. F. (1998). Host densities as determinants of abundance in parasite communities. Proc. R. Soc. B Biol. Sci. 265 (1403), 1283-1289.

Brown, M. J. F., Loosli, R., Schmid-Hempel, P. (2000). Condition-dependent expression of virulence in a trypanosome infecting bumblebees. Oikos 91 (3), 421-427.

Cameron, S. A., Lozier, J. D., Strange, J. P., Koch, J. B., Cordes, N., Solter, L. F., Griswold, T. L. (2011). Patterns of widespread decline in North American bumble bees. Proc. Natl. Acad. Sci. U. S. A. 108 (2), 662-667.

Colla, S. R., Otterstatter, M. C., Gegear, R. J., Thomson, J. D. (2006). Plight of the bumble bee: pathogen spillover from commercial to wild populations. Biol. Conserv. 129 (4), 461-467.

Cremer, S., Armitage, S. A. O., Schmid-Hempel, P. (2007). Social immunity. Curr. Biol. 17 (16), 693-702.

Durrer, S., Schmid-Hempel, P. (1994). Shared use of flowers leads to horizontal pathogen transmission. Proc. R. Soc. B Biol. Sci. 258 (1353), 299-302. 
European Commission (1992). Council Directive 92/65/ EEC. No. L 268/54.

Foulis, E. S. J., Goulson, D. (2014). Commercial bumble bees on soft fruit farms collect pollen mainly from wildflowers rather than the target crops. J. Apic. Res. 53 (3), 404-407.

Freshuelva (2015). http://www.freshuelva.es/ (Accessed 13 November 2015).

Fürst, M. A., McMahon, D. P., Osborne, J. L., Paxton, R. J., Brown, M. J. F. (2014). Disease associations between honeybees and bumblebees as a threat to wild pollinators. Nature 506 (7488), 364-366.

Geslin, B., Aizen, M. A., Garcia, N., Pereira, A.-J., Vaissière, B. E., Garibaldi, L. A. (2017). The impact of honey bee colony quality on crop yield and farmers' profit in apples and pears. Agric. Ecosyst. Environ. 248, 153-161.

Goka, K., Okabe, K., Yoneda, M. (2006). Worldwide migration of parasitic mites as a result of bumblebee commercialization. Popul. Ecol. 48 (4), 285-291.

Goka, K., Okabe, K., Niwa, S., Yoneda, M. (2000). Parasitic mite infestation in introduced colonies of European bumblebees, Bombus terrestris. Japanese J. Appl. Entomol. Zool. 44 (1), 47-50.

González-Varo, J. P., Vilà, M. (2017). Spillover of managed honeybees from mass-flowering crops into natural habitats. Biol. Conserv. 212, 376-382.

Goulson, D. (2010). Bumblebees: behaviour, ecology, and conservation. 2nd ed. Oxford University Press, Oxford, UK.

Goulson, D., Hughes, W. O. H. (2015). Mitigating the anthropogenic spread of bee parasites to protect wild pollinators. Biol. Conserv. 191, 10-19.

Goulson, D., O'Connor, S., Park, K. J. (2018). The impacts of predators and parasites on wild bumblebee colonies. Ecol. Entomol. 43 (2), 168-181.

Graystock, P., Goulson, D., Hughes, W. O. H. (2014). The relationship between managed bees and the prevalence of parasites in bumblebees. PeerJ 2 , e522.

Graystock, P., Goulson, D., Hughes, W. O. H. (2015). Parasites in bloom: flowers aid dispersal and transmission of pollinator parasites within and between bee species. Proc. R. Soc. B Biol. Sci. 282 (1813), 20151371.

Graystock, P., Yates, K., Darvill, B., Goulson, D., Hughes, W. O. H. (2013a). Emerging dangers: deadly effects of an emergent parasite in a new pollinator host. J. Invertebr. Pathol. 114 (2), 114-119.

Graystock, P., Blane, E. J., McFrederick, Q. S., Goulson, D., Hughes, W. O. H. (2016a). Do managed bees drive parasite spread and emergence in wild bees? Int. J. Parasitol. Parasites Wildl. 5 (1), 64-75.

Graystock, P., Meeus, I., Smagghes, G., Goulson, D., Hughes, W. O. H. (2016b). The effects of single and mixed infections of Apicystis bombi and deformed wing virus in Bombus terrestris. Parasitology, 143 (3), 358-365.
Graystock, P., Yates, K., Evison, S. E. F., Darvill, B., Goulson, D., Hughes, W. O. H. (2013b). The Trojan hives: pollinator pathogens, imported and distributed in bumblebee colonies. J. Appl. Ecol. 50 (5), 12071215.

Herrera, J. (1988). Pollination relationships in southern Spanish Mediterranean shrublands. J. Ecol. 76 (1), 274-287.

Imhoof, B., Schmid-Hempel, P. (1999). Colony success of the bumble bee, Bombus terrestris, in relation to infections by two protozoan parasites, Crithidia bombi and Nosema bombi. Insectes Soc. 46 (3), 233-238.

Inoue, M. N., Yokoyama, J., Washitani, I. (2008). Displacement of Japanese native bumblebees by the recently introduced Bombus terrestris (L.) (Hymenoptera: Apidae). J. Insect Conserv. 12 (2), 135-146.

Ishii, H. S., Kadoya, T., Kikuchi, R., Suda, S. I., Washitani, I. (2008). Habitat and flower resource partitioning by an exotic and three native bumble bees in central Hokkaido, Japan. Biol. Conserv. 141 (10), 25972607.

Jabal-Uriel, C., Martín-Hernández, R., Ornosa, C., Higes, M., Berriatúa, E., De la Rúa, P. (2017). First data on the prevalence and distribution of pathogens in bumblebees (Bombus terrestris and Bombus pascuorum) from Spain. Spanish J. Agric. Res. 15 (1), 1-6.

Kuznetsova, A., Brockhoff, P. B., Christensen, R. H. B. (2013). lmerTest: Test for random and fixed effects for linear mixed effect models (lmer objects of lme4 package). R package version 2.0-30.

Macfarlane, R. P., Lipa, J. J., Liu, H. J. (1995). Bumble bee pathogens and internal enemies. Bee World, 76 (3), $130-148$.

Magrach, A., González-Varo, J. P., Boiffier, M., Vilà, M., Bartomeus, I. (2017). Honeybee spillover reshuffles pollinator diets and affects plant reproductive success. Nat. Ecol. Evol. 1 (9), 1299-1307.

Matsumura, C., Yokoyama, J., Washitani, I. (2004). Invasion status and potential ecological impacts of an invasive alien bumblebee, Bombus terrestris L. (Hymenoptera: Apidae) naturalized in Southern Hokkaido, Japan. Glob. Environ. Res. 8 (1), 51-66.

Meeus, I., Brown, M. J. F., De Graaf, D. C., Smagghe, G. (2011). Effects of invasive parasites on bumble bee declines. Conserv. Biol. 25 (4), 662-671.

Morales, C. L., Arbetman, M. P., Cameron, S. A., Aizen, M. A. (2013). Rapid ecological replacement of a native bumble bee by invasive species. Front. Ecol. Environ. 11 (10), 529-534.

Murray, T. E., Coffey, M. F., Kehoe, E., Horgan, F. G. (2013). Pathogen prevalence in commercially reared bumble bees and evidence of spillover in conspecific populations. Biol. Conserv. 159, 269-276.

Ono, M. (1997). Ecological implications of introduced Bombus terrestris, and significance of domestication of Japanese native bumblebees (Bombus spp.). Proc. Int. Work. Biol. Invasions Ecosyst. by Pests Benef. Org. NIAES, Minist. Agric. For. Fish. Japan, Tsukuba, pp. 244-252. 
Osborne, J. L., Martin, A. P., Carreck, N. L., Swain, J. L., Knight, M. E., Goulson, D., Hale, R. J., Sanderson, R. A. (2008). Bumblebee flight distances in relation to the forage landscape. J. Anim. Ecol. 77 (2), 406-415.

Otterstatter, M. C., Whidden, T. L. (2004). Patterns of parasitism by tracheal mites (Locustacarus buchneri) in natural bumble bee populations. Apidologie 35 (4), 351-357.

Otterstatter, M. C., Gegear, R. J., Colla, S. R., Thomson, J. D. (2005). Effects of parasitic mites and protozoa on the flower constancy and foraging rate of bumble bees. Behav. Ecol. Sociobiol. 58 (4), 383-389.

Otti, O., Schmid-Hempel, P. (2007). Nosema bombi: a pollinator parasite with detrimental fitness effects. J. Invertebr. Pathol. 96 (2), 118-124.

Potts, S. G., Imperatriz-Fonseca, V., Ngo, H. T., Aizen, M. A., Biesmeijer, J. C., et al. (2016). Safeguarding pollinators and their values to human well-being. Nature, 540 (7632), 220-229.

R Core Team. (2014). R: A language and environment for statistical computing. Vienna, Austria: R Foundation for Statistical Computing.

van Ravestijn, W., van der Sande, J. (1991). Use of bumblebees for the pollination of glasshouse tomatoes. Acta Hortic. 288, 204-212.

Rutrecht, S. T., Brown, M. J. F. (2009). Differential virulence in a multiple-host parasite of bumble bees: resolving the paradox of parasite survival? Oikos 118 (6), 941-949.

Rutrecht, S. T., Klee, J., Brown, M. J. F. (2007). Horizontal transmission success of Nosema bombi to its adult bumble bee hosts: effects of dosage, spore source and host age. Parasitology 134 (12), 1719-1726.

Sachman-Ruiz, B., Narváez-Padilla, V., Reynaud, E. (2015). Commercial Bombus impatiens as reservoirs of emerging infectious diseases in central México. Biol. Invasions 17 (7), 2043-2053.

Schmid-Hempel, P. (1998). Parasites in social insects. Princeton University Press.

Schmid-Hempel, P. (2005). Evolutionary ecology of insect immune defenses. Annu. Rev. Entomol. 50 , 529-551.
Schmid-Hempel, R., Müller, C. B. (1991). Do parasitized bumblebees forage for their colony? Anim. Behav. 41 (5), 910-912.

Schmid-Hempel, R., Schmid-Hempel, P. (1996). Larval development of two parasitic flies (Conopidae) in the common host Bombus pascuorum . Ecol. Entomol. 21 (1), 63-70.

Schmid-Hempel, R., Eckhardt, M., Goulson, D., Heinzmann, D., Lange, C., Plischuk, S., Escudero, L. R., Salathé, R., Scriven, J. J., Schmid-Hempel, P. (2014). The invasion of southern South America by imported bumblebees and associated parasites. J. Anim. Ecol. 83 (4), 823-837.

Stout, J. C., Morales, C. L. (2009). Ecological impacts of invasive alien species on bees. Apidologie 40 (3), 388-409.

Trillo, A., Herrera, J. M., Vilà, M. (2018). Managed bumble bees increase flower visitation but not fruit weight in polytunnel strawberry crops. Basic Appl. Ecol., 30, 32-40.

Trillo, A., Montero-Castaño, A., González-Varo, J. P., González-Moreno, P., Ortiz-Sánchez, F. J., Vilà, M. (2019). Contrasting occurrence patterns of managed and native bumblebees in natural habitats across a greenhouse landscape gradient. Agric. Ecosyst. Environ., 272, 230-236.

Velthuis, H. H. W., van Doorn, A. (2006). A century of advances in bumblebee domestication and the economic and environmental aspects of its commercialization for pollination. Apidologie, 37 (4), 421-451.

Whitehorn, P. R., Tinsley, M. C., Brown, M. J. F., Goulson, D. (2013). Investigating the impact of deploying commercial Bombus terrestris for crop pollination on pathogen dynamics in wild bumble bees. J. Apic. Res. 52 (3), 149-157.

Yoneda, M., Furuta, H., Kanbe, Y., Tsuchida, K., Okabe, K., Goka, K. (2008). Commercial colonies of Bombus terrestris (Hymenoptera: Apidae) are reservoirs of the tracheal mite Locustacarus buchneri (Acari: Podapolipidae). Appl. Entomol. Zool. 43 (1), 73-76.

Publisher's note Springer Nature remains neutral with regard to jurisdictional claims in published maps and institutional affiliations. 